\title{
Decreased Gas Consumption of a Fluidized Bed Furnace
}

\author{
YONG-CHWANG CHEN
}

The feasibility of utilizing a closed circulatory system to generate gases for a fluidized bed furnace was investigated with the primary concentrations of both economizing on the raw materials used for producing furnace atmospheres and decreasing the air pollution caused by exhaust gases. Air humidified with water vapor was first introduced into a charcoal furnace for causing a reaction with hot charcoal to form a carburizing atmosphere. This atmosphere was then introduced into a fluidized bed furnace to carburize steels. The exhaust gases from the fluidized bed furnace were recycled by repassing them through the hot charcoal layer in the charcoal furnace with a gas pump. The charcoal furnace and the fluidized bed furnace formed a closed circulatory system during the carburization of steels. Experiments were performed with various parameters of this system, including content of water vapor in the humid air, temperature of the charcoal, rate of recirculation of the atmosphere, etc. The effect of each parameter on the carburizing behavior in the fluidized bed furnace was investigated on the basis of the rate of carburization and the carbon potential of the atmosphere. The feasibility of applying this system to a fluidized bed furnace was assessed from the aspects of the fluidization of $\mathrm{Al}_{2} \mathrm{O}_{3}$ powder, the result of carburizing steel, and the rate of consumption of charcoal. The closed system employed in generating atmosphere was demonstrated by the experimental results to have enabled the fluidized bed furnace to operate normally and to have significantly decreased both the consumption rate of charcoal and the environmental pollution.

\section{INTRODUCTION}

FLUIDIZED bed furnaces, in comparison with conventional gas furnaces, possess such advantages as a higher uniform distribution of temperature, a more rapid rate of heating the workpiece, and a briefer period required for heat treatment. Utilization of a fluidized bed furnace in heat treatment of steel is becoming increasingly popular in both Europe and America. ${ }^{[1-4]} \mathrm{A}$ fluidized bed furnace comprises a heat-resistant retort in which a medium of refractory particles, such as $\mathrm{Al}_{2} \mathrm{O}_{3}$, $\mathrm{SiO}_{2}$, etc., is heated while being fluidized by a gas flowing through a porous distributor plate which is located at the bottom of retort. The fluidizing gas depends on the process to be carried out in the furnace. Nitrogen is employed for neutral heating, nitrogen/ammonia mixtures for nitriding, and nitrogen/propane/air or nitrogen $/$ methanol/methane mixtures for carburizing. A fluidized bed furnace is generally operated in an open system, i.e., gases are introduced from the bottom and then exhausted to the air from the top of the furnace. The operating procedure is illustrated as follows, with an example of carburization being cited. Parts are lowered into the fluidized bed which is operated on nitrogen, usually at a working temperature of $900^{\circ} \mathrm{C}$ to $1000^{\circ} \mathrm{C}$. The nitrogen flow continues until the parts reach the carburization temperature. At this time, methanol is introduced into the furnace together with nitrogen and a small quantity of methane. The carbon potential of furnace atmosphere is controlled by the additional level of methane. At the end of carburization, the atmosphere is purged with nitrogen for about 2 minutes; the parts are then quenched in oil.

YONG-CHWANG CHEN, Associate Professor, is with the Department of Mechanical Engineering, National Taiwan University,

Taipei, Taiwan 10764, Republic of China.

Manuscript submitted November 30, 1992.
The gas flow of a fluidized bed furnace, as compared with that of a conventional gas furnace, needs maintaining at a relatively higher level to make the refractory particles become fluidized. The gas consumption of a fluidized bed furnace consequently exceeds that of a conventional gas furnace. This property is the major shortcoming of a fluidized bed furnace. Recycling of the atmospheres of fluidized bed furnaces was investigated for the purpose of decreasing gas consumption. For general approaches, the exhaust gas of a fluidized bed furnace was recirculated with a gas pump after this exhaust gas had been mixed with an appropriate amount of enriching gas, such as $\mathrm{CH}_{4}, \mathrm{C}_{3} \mathrm{H}_{8}$, etc. The recycling percentage of atmospheres for this method is relatively small, ranging from 50 to 80 pct. ${ }^{[4]}$ Control of the carbon potential is relatively complicated, because the carbon potential of the recycled atmosphere depends not only on the amount of enriching gas but also on the composition of the exhaust gas.

The gaseous mixture generated by reacting humid air with hot charcoal has been found to possess a carburizing capability for steel. ${ }^{[5]}$ The composition of this mixture depends on the water vapor content of the humid air and the temperature of charcoal. For example, the theoretical equilibrium composition is $36.77 \mathrm{pct} \mathrm{CO}$, 9.16 pct $\mathrm{H}_{2}, 0.427$ pct $\mathrm{CO}_{2}, 0.132$ pct $\mathrm{H}_{2} \mathrm{O}, 0.013$ pct $\mathrm{CH}_{4}$, and balance $\mathrm{N}_{2}$ for water vapor content of $12.1 \mathrm{pct}$ and charcoal temperature of $900^{\circ} \mathrm{C}$. The content of $\mathrm{CO}$ slightly decreases and the content of both $\mathrm{CO}_{2}$ and $\mathrm{H}_{2} \mathrm{O}$ slightly increases once a carburizing reaction has occurred; the carbon potential consequently decreases. The carbon potential of the mixture can, however, be recovered on passage of the mixture again through a hot charcoal layer. The consumption of charcoal is relatively small, because the difference in chemical composition of the mixture before and after passage through the hot charcoal layer is minute. 


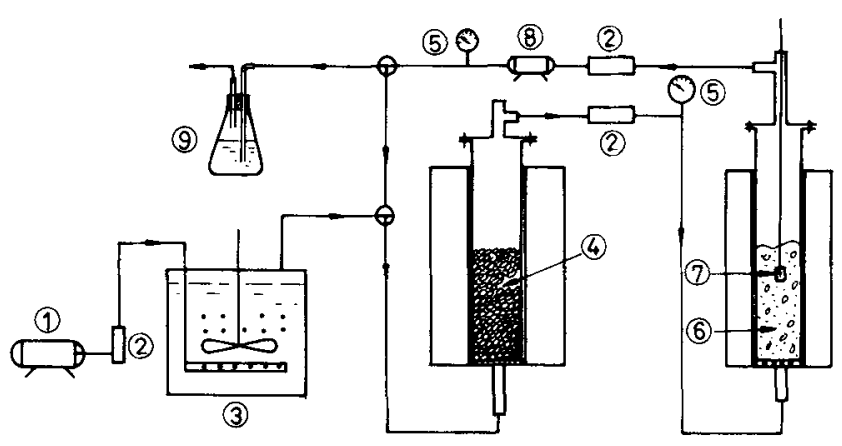

(1) Air pump

(4) Charcoal

(2) Flowmeter

(5) Pressure gage

(7) Specimen

(3) Water bath

(6) $\mathrm{Al}_{2} \mathrm{O}_{3}$ powder

(8) Circulation pump

(9) Bleeder

Fig. 1 -Experimental apparatus.

The purpose of this work lied in understanding the possibility of economizing on raw material of gases for a fluidized bed furnace by applying the preceding principle. A carburizing atmosphere was first generated by introducing humid air into a charcoal furnace to react with hot charcoal. The atmosphere was then introduced into a fluidized bed furnace to carburize steel. The exhaust gas from the fluidized bed furnace was recycled after recovery of its carbon potential on passage again through the charcoal furnace. Experiments were performed for elucidating the effects of temperature of charcoal, content of water vapor of the humid air, and rate of circulation of the atmosphere on the carburizing behavior in the fluidized bed furnace. The feasibility of applying this system for generating the atmosphere to a fluidized bed furnace was evaluated on the basis of the previous experimental results.

\section{EXPERIMENTAL METHOD}

The experimental apparatus is schematically shown in Figure 1, and the experimental conditions are summarized in Table I. Air was first pumped into an isothermal water bath at a rate of $1.5 \mathrm{~L} / \mathrm{min}$ to be humidified with water vapor. The humid air was then introduced into a charcoal furnace to generate an atmosphere of $\mathrm{N}_{2}+$ $\mathrm{CO}+\mathrm{H}_{2}+\mathrm{CO}_{2}+\mathrm{H}_{2} \mathrm{O}+\mathrm{CH}_{4}$. This atmosphere was next passed through the fluidized bed furnace and was finally exhausted to the air from a bleeder. The system was closed and the circulation pump was started after the original gas in the system had been substituted by the specific atmosphere. The rate of circulation of the atmosphere was regulated by controlling the speed of the circulation pump or adjusting the needle valve of the flowmeter. The circulation rate of the atmosphere was properly regulated so that the $\mathrm{Al}_{2} \mathrm{O}_{3}$ powder could be uniformly fluidized. A steel sample, hung by a $\mathrm{Ni}-\mathrm{Cr}$ wire beforehand, was placed at the specific location in the fluidized bed to be heated once the furnace condition had achieved a steady state.

The retort of the fluidized bed furnace, having an internal diameter of $100 \mathrm{~mm}$ and a length of $470 \mathrm{~mm}$, was made of INCONEL ${ }^{*} 601$. A plate to distribute gas was

*INCONEL is a trademark of Inco Alloys International, Inc., Huntington, WV.

placed at the bottom of the retort. $\mathrm{A}$ layer of $\mathrm{Al}_{2} \mathrm{O}_{3}$ with a particle size in the range 4 to 10 mesh was placed on the plate to unify the gas flow. $\mathrm{A}$ layer of $\mathrm{Al}_{2} \mathrm{O}_{3}$ powder with a mean diameter $100 \mu \mathrm{m}$ of particles was then filled into the retort to a length of $90 \mathrm{~mm}$ as the fluidized medium. The condition of fluidization of the $\mathrm{Al}_{2} \mathrm{O}_{3}$ powder was observed through a window in the upper cover of the retort.

The retort in the charcoal furnace was made of INCONEL 601, with an internal diameter of $120 \mathrm{~mm}$ and a length of $700 \mathrm{~mm}$. Pretreated charcoal chips in the range 5 to 16 mesh filled the retort to a height of $330 \mathrm{~mm}$. The dimensions of the water bath are $500 \times$ $500 \times 750 \mathrm{~mm}$, which was filled with water to a depth $600 \mathrm{~mm}$. The air piping from an air pump was located at the bottom of the water bath. Many small holes were drilled through the pipe wall so that the introduced air could form small bubbles to bring water vapor to saturation at the temperature of the water bath. The higher water vapor content in the humid air occurred for the higher temperature of the water bath. The water vapor content in the humid air was thus controlled by means of the water bath temperature. The connecting pipe from the water bath to the charcoal furnace was heated with a resistance wire to avoid the condensation of water vapor from the humid air during transport.

Steel samples used include two types: a low carbon steel foil of Japanese Industrial Standard-Extra Deep Drawing Cold Plate Steel (JIS-SPCE) with a thickness of $0.05 \mathrm{~mm}$ and a disk of pure iron with a thickness of $2 \mathrm{~mm}$ and a diameter of $15 \mathrm{~mm}$. A specimen of the former type, having dimensions of $10 \times 15 \times 0.05 \mathrm{~mm}$, was employed for testing the equilibrium carbon content of steels (or the carbon potential of the atmosphere) upon heat treatment in the fluidized bed furnace. A specimen of the latter type was employed for testing the hardness distribution in the carburized and quenched case of steel.

Table I. Experimental Conditions

\begin{tabular}{|c|c|c|c|c|c|c|}
\hline \multirow[b]{3}{*}{ Condition } & \multirow{2}{*}{\multicolumn{3}{|c|}{ Generation Condition of Atmosphere }} & \multicolumn{3}{|c|}{ Steel Sample Heating Condition } \\
\hline & & & & & Temperature & \\
\hline & Water Bath $\left({ }^{\circ} \mathrm{C}\right)$ & Charcoal $\left({ }^{\circ} \mathrm{C}\right)$ & Circulation Rate (L/min) & Sample & $\left({ }^{\circ} \mathrm{C}\right)$ & Time $(\mathrm{min})$ \\
\hline 1 & 60 & 1000 & $4,6,8,10$ & SPCE & 933 & 1 to 15 \\
\hline 2 & $40,50,60$ & $1000,1050,1100$ & 8 & SPCE & 933 & 1 to 15 \\
\hline 3 & 60 & 1050 & 4,8 & - & 933 & - \\
\hline 4 & 60 & 1000 & 8 & pure iron & 933 & 60,180 \\
\hline
\end{tabular}


The chemical compositions of those steel samples appear in Table II.

\section{RESULTS}

\section{A. The Fluidization Condition of a Fluidized Bed in a Closed Circulatory System}

Fluidized bed furnaces are generally operated in an open system; i.e., the atmosphere is introduced into the furnace from the bottom of the retort and exhausted to the air from the top of the retort. The following experiment was done for understanding whether the $\mathrm{Al}_{2} \mathrm{O}_{3}$ powder in the retort could be normally fluidized in a closed circulatory system or not. The outlet and inlet of the retort were connected to the inlet and outlet of a gaspumping unit, respectively, comprising a circulation pump and a flowmeter. The circulation rate of the atmosphere was regulated by adjusting the needle valve of the flowmeter. The fluidization condition of $\mathrm{Al}_{2} \mathrm{O}_{3}$ powder was observed from the transparent window at the top of the retort. $\mathrm{Al}_{2} \mathrm{O}_{3}$ powder was observed to become uniformly fluidized whenever the rate of circulation of the atmosphere reached $4 \mathrm{~L} / \mathrm{min} ; \mathrm{Al}_{2} \mathrm{O}_{3}$ powder was not carried from the retort as long as the circulation rate of the atmosphere was less than $10 \mathrm{~L} / \mathrm{min}$. This fluidization condition of the $\mathrm{Al}_{2} \mathrm{O}_{3}$ powder was similar to that in an open system. This phenomenon has implied that the fluidization condition of a fluidized bed is essentially determined by the velocity of the gas flowing through the layer of $\mathrm{Al}_{2} \mathrm{O}_{3}$ powder, regardless of whether the system is open or closed.

\section{B. The Effect of the Circulation Rate of Atmosphere on the Carburizing Behavior}

The velocity of atmospheres affects the carburizing behavior in a conventional furnace; i.e., both the rate of carburization and the carbon potential of atmospheres increase with increasing velocity of the atmosphere. Experiments were done in accordance with condition 1 in Table I for the sake of discovering whether a similar phenomenon exists in a closed system or not. The temperatures of the water bath and charcoal furnace were set at $60^{\circ} \mathrm{C}$ and $1000^{\circ} \mathrm{C}$, respectively. The temperature of the fluidized bed furnace was controlled at $933{ }^{\circ} \mathrm{C}$. Atmospheres were generated and recirculated in the closed system. The rate of circulation of the atmosphere was controlled at $4,6,8$, and $10 \mathrm{~L} / \mathrm{min}$, respectively. The SPCE samples were heated in the fluidized bed furnace for durations of 1 to 15 minutes, with the retort having $\mathrm{Al}_{2} \mathrm{O}_{3}$ powder and not having $\mathrm{Al}_{2} \mathrm{O}_{3}$ powder, respectively. The relationship between heating period and carbon content of the heated specimen is shown in Figure 2 for those conditions lacking $\mathrm{Al}_{2} \mathrm{O}_{3}$ powder in the retort. Diagrams (a) through (d) indicate those results when the circulation rates of atmosphere were $4,6,8$, and $10 \mathrm{~L} / \mathrm{min}$, respectively. The slope of each curve therein represents the rate of carburizing steel, and the carbon content indicated by the horizontal part of each curve is the equilibrium carbon content of steel, namely, the carbon potential of the atmosphere. The curves in diagrams (a) through (d) are plotted together in diagram (e) for a convenient comparison. Both the rate of carburizing steel and the carbon potential of the atmosphere increase with the increasing rate of circulation of the atmosphere. This phenomenon is similar to that in a conventional open furnace. The relationship between the heating period and carbon content of the heated sample appears in Figure 3 for the retort filled with $\mathrm{Al}_{2} \mathrm{O}_{3}$ powder. Neither the carburizing rate nor carbon potential varies significantly no matter whether the circulation rate of atmosphere is $4,6,8$, or $10 \mathrm{~L} / \mathrm{min}$. The carburizing result in a fluidized bed at a rate $4 \mathrm{~L} / \mathrm{min}$ of circulation of the atmosphere is nearly the same as that in a nonfluidized bed at a rate $10 \mathrm{~L} / \mathrm{min}$ of circulation. Carburization in a fluidized bed is therefore superior to that in a conventional furnace.

\section{The Effect of the Content of Water Vapor in Humid Air on Carburizing Behavior}

Experiments were conducted according to condition 2 in Table I to establish how the content of water vapor in humid air affected the carburizing behavior in the fluidized bed furnace. Various proportions of water vapor were added to air by introducing this air into the water bath at various temperatures. Atmospheres were generated by reacting the humid air with hot charcoal at various temperatures. The circulation rate of atmospheres was controlled at $8 \mathrm{~L} / \mathrm{min}$. The SPCE samples were heated at $933{ }^{\circ} \mathrm{C}$ in the fluidized bed furnace. The relationship between period of heating and carbon content of the heated samples is shown in Figure 4(a) for the charcoal temperature of $1000{ }^{\circ} \mathrm{C}$. The carburizing rate increases with increasing temperature of the water bath (or increasing proportion of water vapor in air). The carbon potential, however, does not significantly increase when the temperature of the water bath increases. A similar result appears in Figure 4(b) for the charcoal temperature $1050{ }^{\circ} \mathrm{C}$. The experimental result for the charcoal temperature $1100{ }^{\circ} \mathrm{C}$ appears in Figure 4(c). Both the carburizing rate and carbon potential are indicated from this diagram to have increased once the content of water vapor in the humid air increased. Furthermore, both the carburizing rate and carbon potential are indicated from the corresponding curves in diagrams (a) through (c) to have a tendency to increase with increasing temperature of the charcoal.

Table II. Chemical Composition of Steel Samples

\begin{tabular}{lccccccc}
\hline & \multicolumn{5}{c}{ Chemical Composition (Wt Pct) } \\
\cline { 2 - 6 } Steel Sample & $\mathrm{C}$ & $\mathrm{Si}$ & $\mathrm{Mn}$ & $\mathrm{P}$ & $\mathrm{S}$ & $\mathrm{Fe}$ \\
\hline SPCE & 0.057 & 0.008 & 0.28 & 0.023 & 0.022 & bal. \\
Pure iron & 0.015 & 0.005 & 0.068 & 0.010 & 0.008 & bal. \\
\hline
\end{tabular}



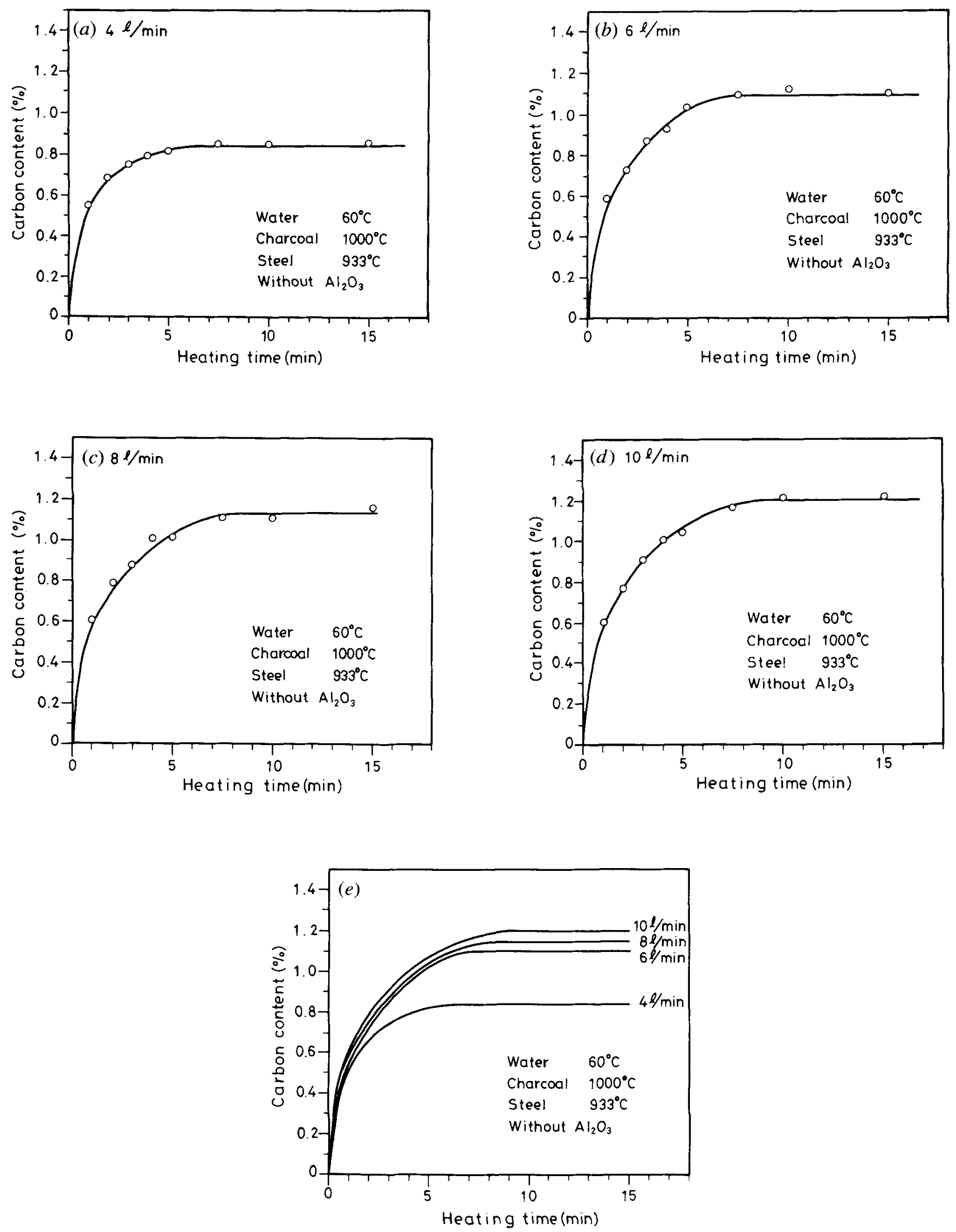

Fig. 2-(a) through (e) Relationship between time and carbon content of SPCE heated under the atmosphere at various circulation rates in the retort without $\mathrm{Al}_{2} \mathrm{O}_{3}$ powder. 


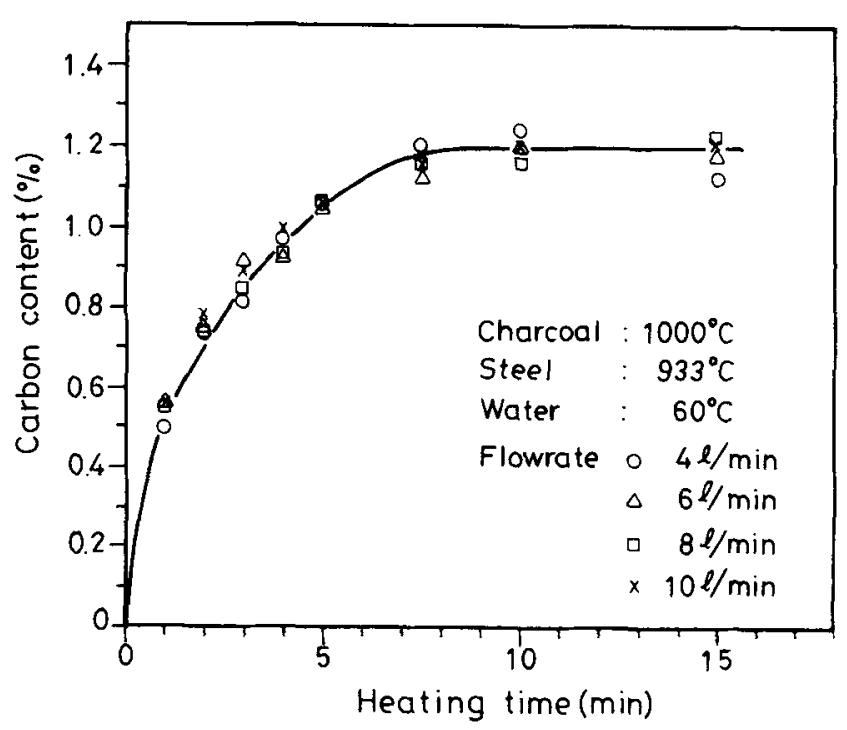

Fig. 3-Relationship between time and carbon content of SPCE heated under the atmosphere at various circulation rates in the retort filled with $\mathrm{Al}_{2} \mathrm{O}_{3}$ powder.

\section{The Chemical Composition of Atmospheres}

The air humidified with water vapor by passage into the water bath at a rate of flow $1.5 \mathrm{~L} / \mathrm{min}$ was introduced into the charcoal furnace to generate furnace atmospheres. The chemical composition of the atmosphere was analyzed via a gas chromatography (Table III). The components of the atmosphere are $\mathrm{N}_{2}, \mathrm{CO}, \mathrm{H}_{2}$, and $\mathrm{CO}_{2}$ in an order of decreasing proportion. Increasing the temperature of the water bath (or increasing the amount of water vapor added) at a constant charcoal temperature leads to a significant increase in content of $\mathrm{H}_{2}$, a slight increase of $\mathrm{CO}$, but no significant change of $\mathrm{CO}_{2}$. Increasing the temperature of charcoal results in a decrease of $\mathrm{CO}_{2}$, but no significant alteration of either $\mathrm{H}_{2}$ or $\mathrm{CO}$ if the temperature of water bath remains constant. The minimum gaseous content that can be detected by the gas analyzer was $0.1 \mathrm{pct}$. When the temperature of charcoal was increased to $1100{ }^{\circ} \mathrm{C}$, the content of $\mathrm{CO}_{2}$ was decreased to below 0.1 pct and could not be detected by the gas analyzer. The atmosphere theoretically contains $\mathrm{CH}_{4}$ as well, but this content was so small that it could not be detected.

Experiments were carried out according to condition 3 in Table I for establishing whether the chemical composition of these atmospheres remained steady while circulating in the system. Atmospheres were recirculated in the closed system at circulation rates of 4 and $8 \mathrm{~L} / \mathrm{min}$, respectively. A gaseous sample was withdrawn and analyzed at 1 hour intervals. The relationship between the duration of circulation and the content of $\mathrm{CO}$ and $\mathrm{CO}_{2}$ of the atmosphere appears in Figure 5. Both the $\mathrm{CO}$ and $\mathrm{CO}_{2}$ contents of the atmosphere were steady and affected little by duration and rate of circulation of the atmosphere. The content of $\mathrm{CO}$ remained at approximately $38 \mathrm{pct}$ and $\mathrm{CO}_{2}$ at approximately 0.2 pct. The carburizing behavior in the fluidized bed furnace is determined by content of $\mathrm{CO}$ and $\mathrm{CO}_{2}$. The carburizing reaction therefore does not change if neither $\mathrm{CO}$ nor $\mathrm{CO}_{2}$ content changes. The carburization of steel in the fluidized bed furnace consequently becomes steady. The same carburizing result is obtained even if the rate of circulation is altered. This deduction is consistent with the results of Figure 3.

\section{E. The Hardness Distribution in the Carburized Case}

The main purpose of steel carburization lies in forming a case with great hardness. Experiments were conducted according to condition 4 in Table $I$ to obtain the results of carburizing steel in the fluidized bed of a closed circulatory system. Pure iron specimens were carburized in the fluidized bed for 1 or 3 hours, followed by water quenching. The distribution of hardness in the surface layer of the carburized and quenched specimens is shown in Figure 6. The carburized layer of the specimen after quenching was hardened significantly. The surface hardness reached approximately $\mathrm{Hv} 800$. The thickness of the effective hardened layer with a hardness greater than $\mathrm{Hv} 400$ is approximately 0.4 and $0.9 \mathrm{~mm}$ for the specimens carburized for 1 and 3 hours, respectively. Therefore, carburization of steels can be satisfactorily carried out in a fluidized bed furnace with a system which generates a circulatory atmosphere.

\section{DISCUSSION}

\section{A. The Effect of Velocity of the Atmosphere on Carburizing Behavior}

Both the rate of carburizing and the carbon potential increase with increasing velocity of the atmosphere for steels carburized in a conventional gas furnace. The reason for this phenomenon is accounted for as follows. Decarburizing gases, such as $\mathrm{CO}_{2}$ and $\mathrm{H}_{2} \mathrm{O}$, are produced after a carburizing reaction occurs. These decarburizing gases decrease the carbon potential of the atmosphere near the steel surface and retard the carburizing reaction. The carburizing reaction continues only after these decarburizing gases leave the surface of steel. Increasing the velocity of the atmosphere not only assists these decarburizing gases in leaving the steel surface but also increases the collision frequency between the fresh atmosphere and the steel. Both the rate of carburizing and the carbon potential consequently increase with an increasing velocity of the atmosphere. This is consistent with the results in Figure 2.

Both the rate of carburizing and the carbon potential in a fluidized bed are illustrated in Figure 3 to alter little no matter whether the circulation rate of atmosphere is, $4,6,8$, or $10 \mathrm{~L} / \mathrm{min}$. The reason is that $\mathrm{Al}_{2} \mathrm{O}_{3}$ powder is already completely fluidized once the flow rate of the atmosphere reaches $4 \mathrm{~L} / \mathrm{min}$. The decarburizing gases $\mathrm{CO}_{2}$ and $\mathrm{H}_{2} \mathrm{O}$, which are generated as a result of the carburizing reaction, can be immediately removed from the surface of steel owing to the agitation of the fluidized $\mathrm{Al}_{2} \mathrm{O}_{3}$ powder. The composition of the gases near the surface of steel is the same as long as the flow rate exceeds $4 \mathrm{~L} / \mathrm{min}$. Therefore, neither the rate of carburizing nor the carbon potential increases with further increasing of the velocity of atmosphere. On the contrary, some $\mathrm{CO}_{2}$ and $\mathrm{H}_{2} \mathrm{O}$ gases, products of carburization, may possibly adhere onto the surface of steel in a conventional 

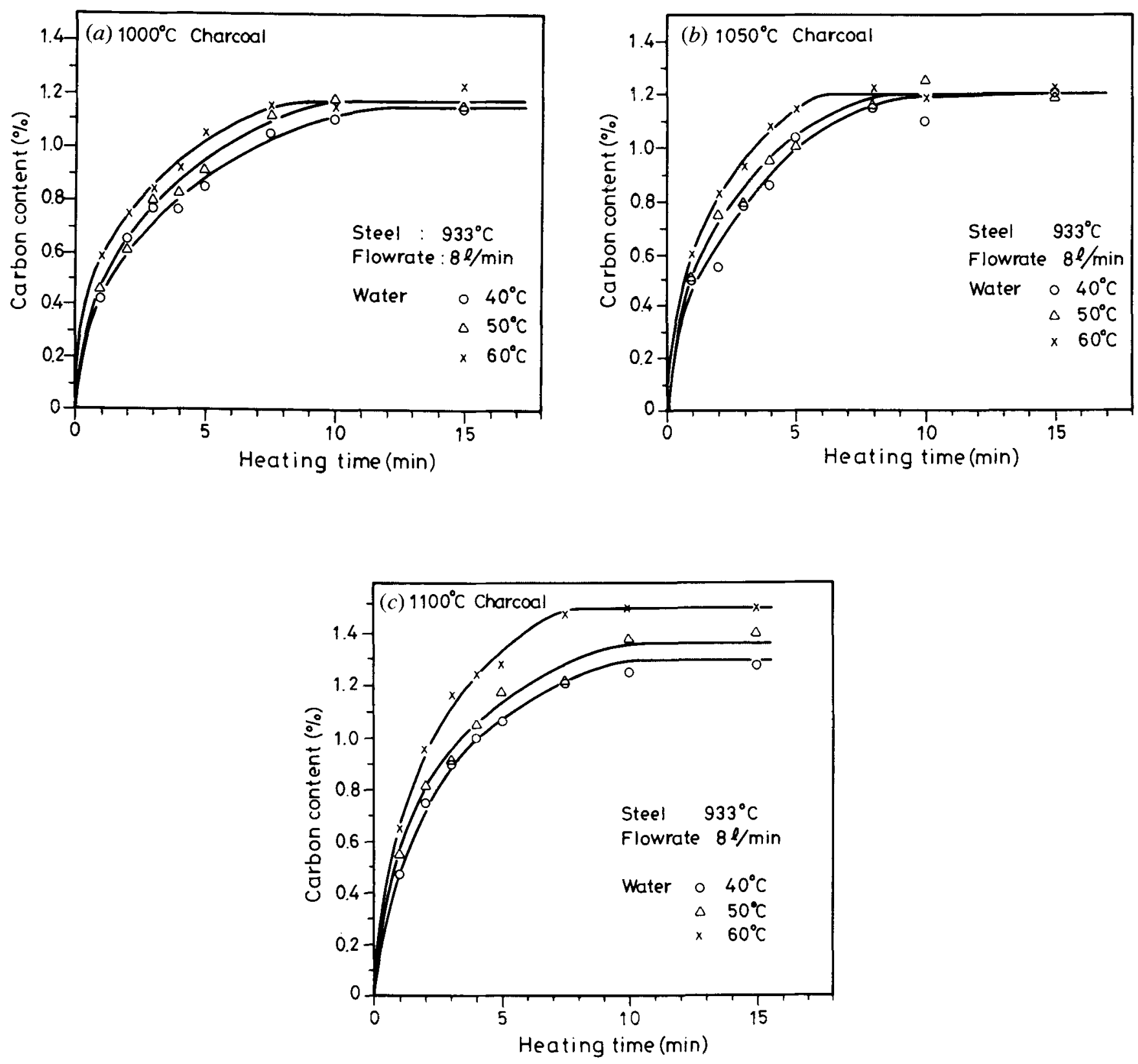

Fig. 4-Relationship between time and carbon content of SPCE heated in the fluidized bed under the atmosphere generated by reacting humid air with hot charcoal at $(a) 1000{ }^{\circ} \mathrm{C},(b) 1050{ }^{\circ} \mathrm{C}$, and (c) $1100{ }^{\circ} \mathrm{C}$.

furnace because of a lack of agitation of $\mathrm{Al}_{2} \mathrm{O}_{3}$ powder. The composition of the gases near the surface of steel depends on the velocity of atmosphere. The higher the velocity of atmosphere, the sooner the products of carburization become removed from the surface of steel and the lower the content of $\mathrm{CO}_{2}$ and $\mathrm{H}_{2} \mathrm{O}$ occurs. Both the carburizing rate and carbon potential consequently increase with increasing the velocity of atmosphere. As a result, the rate of carburizing in a fluidized bed furnace (as compared to that in a conventional gas furnace) may be more rapid and steadier.

\section{B. The Effects of Content of Water Vapor and Charcoal Temperature on Carburizing Behavior}

The carburizing rate in the fluidized bed (Figure 4) increases with increasing content of water vapor in humid air if the charcoal temperature remains constant. The reason is that the rate of carburizing of an atmosphere is determined by its content of $\mathrm{CO}$ and $\mathrm{H}_{2}$; both these contents of the present atmosphere are indicated in Table III to increase with the water vapor content of the humid air. The carbon potential of the atmosphere at charcoal temperatures of $1000^{\circ} \mathrm{C}$ and $1050{ }^{\circ} \mathrm{C}$ is illustrated in Figures 4(a) and (b) to increase little with increasing water vapor content of the humid air. The carbon potential of the atmosphere at a charcoal temperature of $1100{ }^{\circ} \mathrm{C}$ is observed in Figure $4(\mathrm{c})$ to significantly increase with the content of water vapor of the humid air. The reason for this phenomenon follows.

The atmosphere has a definite equilibrium composition once the reaction between hot charcoal and humid air, which contains a specific proportion of water vapor, 
Table III. Chemical Composition

of the Atmosphere Generated by Reacting

Humid Air with Hot Charcoal at Various Temperatures of Water Bath and Charcoal Furnace

\begin{tabular}{cccccc}
\hline $\begin{array}{c}\text { Charcoal } \\
\text { Furnace } \\
\left({ }^{\circ} \mathrm{C}\right)\end{array}$ & $\begin{array}{c}\text { Water } \\
\text { Bath } \\
\left({ }^{\circ} \mathrm{C}\right)\end{array}$ & \multicolumn{4}{c}{ Volume Percentage $($ Pct $)$} \\
\cline { 4 - 6 } \cline { 4 - 6 } & 4000 & $\mathrm{~N}_{2}$ & $\mathrm{CO}$ & \multicolumn{1}{c}{$\mathrm{H}_{2}$} & $\mathrm{CO}_{2}$ \\
\hline 1000 & 50 & bal. & 36.4 & 6.0 & 0.23 \\
1000 & 60 & bal. & 37.9 & 7.5 & 0.23 \\
1050 & 40 & bal. & 38.8 & 12.5 & 0.23 \\
1050 & 50 & bal. & 35.6 & 6.3 & 0.11 \\
1050 & 60 & bal. & 38.3 & 7.9 & 0.11 \\
1100 & 40 & bal. & 35.2 & 6.7 & $* .12$ \\
1100 & 50 & bal. & 36.3 & 7.3 & $*$ \\
1100 & 60 & bal. & 38.4 & 12.2 & $*$ \\
\hline
\end{tabular}

*Too lean to be detected by gas analyzer.

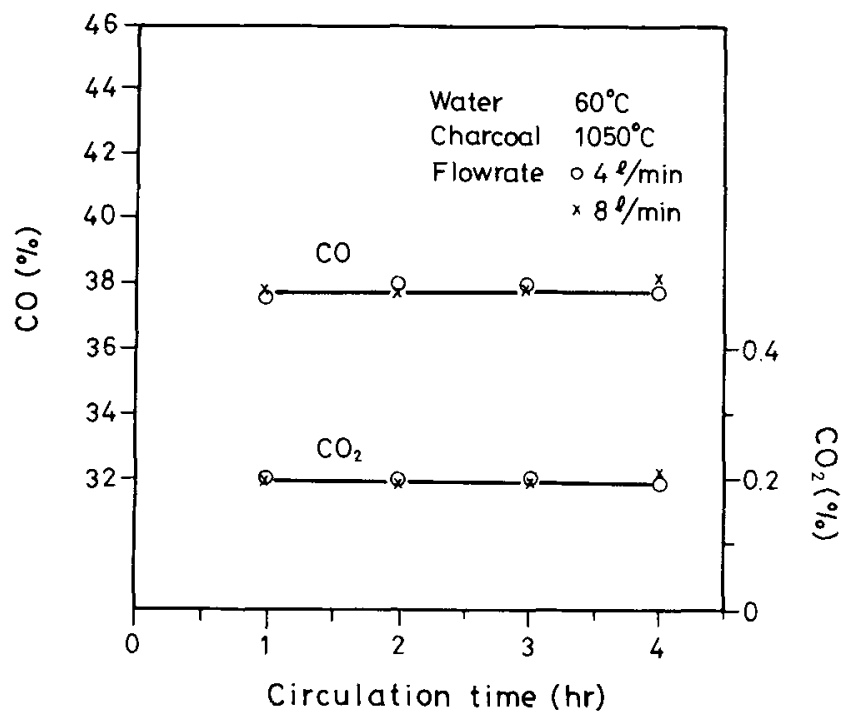

Fig. 5-Relationship between circulation duration and content of $\mathrm{CO}$ and $\mathrm{CO}_{2}$ of the atmosphere recirculated in the closed system at flow rates of 4 and $8 \mathrm{~L} / \mathrm{min}$.

reaches an equilibrium state. The steel heated in this equilibrium atmosphere obtains a specific equilibrium carbon level which represents the carbon potential of the atmosphere. The carbon potential of the atmosphere is theoretically determined when the content of water vapor of the humid air, charcoal temperature, and steel temperature all become specified. ${ }^{[5]}$ The relationships among them appear in Figure 7, in which the temperatures inscribed beside the curves are charcoal temperatures. The carbon potential of the atmosphere is shown there to increase with increasing temperature of the charcoal when both the content of water vapor of humid air and the heating temperature of steel are kept constant, which is consistent with those results of Figure 4 . The carbon potential of the atmosphere is shown in Figure 7 to increase with increasing content of water vapor of humid air if both charcoal temperature and steel temperature are kept unchanged. This is consistent with the results of Figure 4(c) but inconsistent with those of

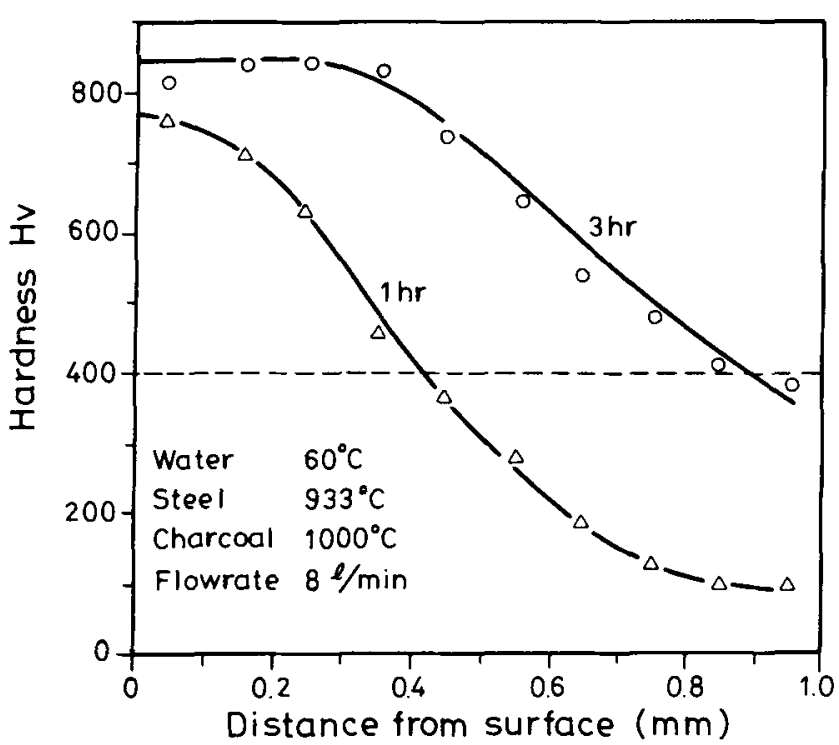

Fig. 6-Distribution of hardness in the surface layer of pure iron carburized in the fluidized bed furnace for 1 and 3 hours followed by water quenching.

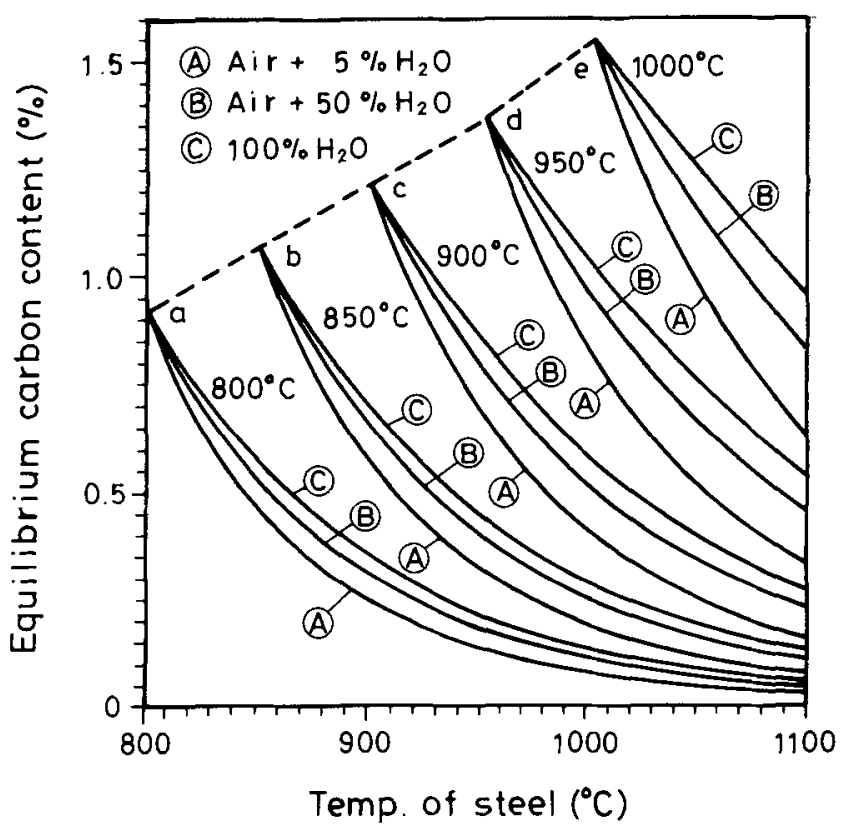

Fig. 7-Relationship between heating temperature of steel and theoretical carbon potential of the atmosphere generated by reacting humid air with hot charcoal.

Figures 4(a) and (b). Figure 7 contains calculated results, assuming that the reaction between humid air and hot charcoal achieves equilibrium. The more rapid reaction occurs between humid air and charcoal for the greater charcoal temperature. The reaction consequently achieves equilibrium more easily at a greater temperature. If the temperature of charcoal is not great enough, the water vapor in the humid air cannot completely react with the hot charcoal and some water vapor may possibly remain in the atmosphere. The water vapor in an atmosphere greatly inhibits the carburizing reaction. This effect accounts for the results of Figures 4(a) and 
(b); i.e., the carbon potential of the atmosphere increases little when the content of water vapor in the humid air increases at charcoal temperatures of $1000{ }^{\circ} \mathrm{C}$ and $1050{ }^{\circ} \mathrm{C}$.

\section{The Consumption of Raw Material to Produce Atmospheres}

The great consumption of gases is the primary disadvantage of a fluidized bed furnace. This work has generated atmospheres from charcoal for the fluidized bed furnace in a closed circulatory system with the aim of economizing on the raw material of atmospheres. Gases in this system were not exhausted to the air but circulated between the charcoal furnace and the fluidized bed furnace during the carburization of steels. The atmosphere functioned just as a carrier of carbon which repeatedly brought carbon from charcoal to steel. By neglecting the sooting in the system, the weight decrease of charcoal became theoretically equivalent to the weight increase of steel owing to carburization. Thus, the consumption of charcoal in the closed recirculating system is relatively small as compared with that of an open system. The experiment regarding consumption of charcoal in open and closed systems was performed in tubeshaped furnaces. ${ }^{[6]}$ In Figure 8, the horizontal axis represents the volume of gases flowing through the carburizing furnace and the vertical axis denotes the consumption of charcoal. A linear relationship arises between the charcoal consumption and the volume of the atmosphere for both systems. Accordingly, the consumption rate of charcoal in the closed system is observed from a comparison of the two lines in the slopes to be only approximately $1 / 30$ of that in the open system. As for the system which generates the atmosphere in the present work, the height of charcoal did not significantly decrease after carburization in the fluidized bed furnace for 72 hours. This closed system which generates the atmosphere clearly has great potential for

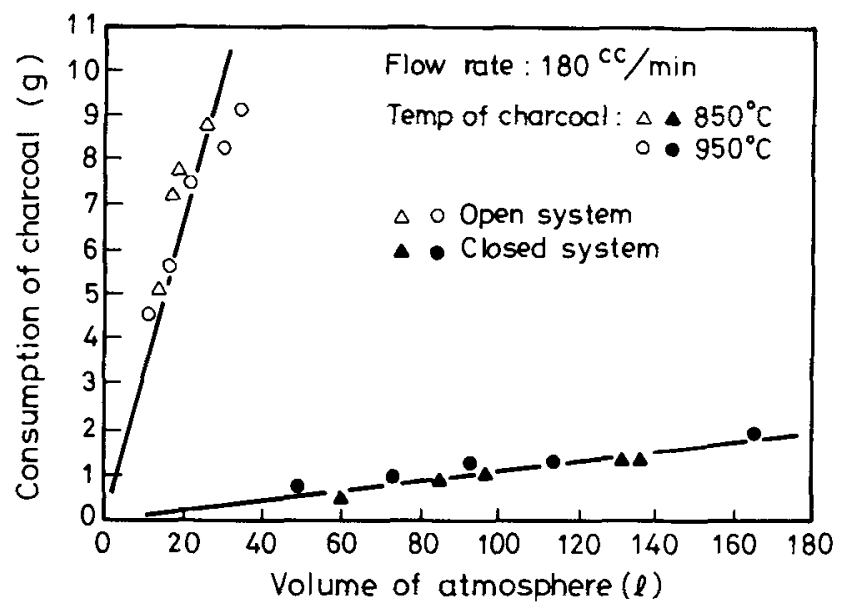

Fig. 8-Comparison of charcoal consumption for generating atmospheres by reacting water vapor with hot charcoal in an open system and a closed system. economy of the raw materials required to produce these atmospheres.

\section{Comparison with General Approaches}

As previously stated, general approaches employed for economizing on atmospheres of a fluidized bed furnace aim at recycling these atmospheres after they are mixed with enriching gases. The efficiency of atmospheric recycling by this method cannot theoretically attain 100 pct because of the addition of enriching gases. Some atmosphere has to be exhausted to the air; otherwise, the pressure of the system increases. According to previous investigations, the efficiency of atmospheric recycling of this method reached 80 pct at most. ${ }^{[4]}$ As for the closed atmosphere-generating system used in the present work, no atmosphere was exhausted to the air during the period of carburization. The recycling efficiency of atmosphere consequently attained nearly 100 pct, which is one of the benefits of this system.

Furthermore, new atmospheres are obtained by mixing exhausted gases with enriching gases for general approaches to refresh the atmospheres. The carbon potential of a new atmosphere closely correlates with both the chemical composition of the exhausted gases and the added level of enriching gases. The carbon potential of atmospheres also affects the chemical composition of exhausted atmospheres. This chain relationship causes the control of carbon potential to become relatively complicated. In the atmospheregenerating system used in this study, new atmospheres were obtained by passing exhausted atmospheres through hot charcoal again. The new atmosphere theoretically reached a definite equilibrium chemical composition and possessed a definite carbon potential for a given temperature of charcoal no matter what the chemical composition of the exhausted atmosphere was. The greater carbon potential of the atmosphere occurred for the greater charcoal temperature. Thus, the carbon potential of the atmosphere has become easily controlled by means of the charcoal temperature, which is yet another benefit of this system.

\section{CONCLUSIONS}

The following concluding remarks can be made on the basis of discussion in this article.

1. The $\mathrm{Al}_{2} \mathrm{O}_{3}$ powder within a fluidized bed furnace in a closed system can be uniformly fluidized if the circulation rates of the atmosphere in the system are properly regulated.

2. The carburization of steels in this system is effectively controlled by means of the water vapor content of humid air and the charcoal temperature. The more rapid carburizing rate at a given temperature of the charcoal occurs for the greater water vapor content of humid air. The greater carbon potential of atmospheres for a given content of water vapor of humid air occurs for the greater charcoal temperature.

3 . Both the chemical composition of atmospheres and the result of carburizing steels in a fluidized bed 
furnace employing a system which generates a circulatory atmosphere are so steady that they are scarcely affected by the duration or the circulation rate of atmospheres.

4. In comparison with general approaches to economizing on atmospheres, the closed circulatory system used in this present work has a greater efficiency for recycling atmospheres and is also relatively simple for control of the carbon potential of the atmospheres.

5. Using a fluidized bed furnace with a system which generates a circulating atmosphere to perform carburization of steel not only produces satisfactory carburizing but also significantly decreases the consumption of raw material of atmospheres and also avoids the air pollution caused by the exhausted gases.

\section{ACKNOWLEDGMENT}

The author is very grateful to the National Science Council of Taiwan, Republic of China, for its financial support of this research under Grant No. NSC-80-0401E-002-33.

\section{REFERENCES}

1. P. Sommer: Heat Treat. Met., 1987, vol. 14 (1), pp. 7-10.

2. J. Jasinski, L. Jeziorski, and M. Kubara: Heat Treat. Met., 1985, vol. 12 (2), pp. 41-46.

3. R.W. Reynoldson: Heat Treat. Met., 1980, vol. 7 (2), pp. 35-40.

4. T. Fukuda and H. Hattori: Heat Treat. Met., 1988, vol. 15 (3), pp. 53-58.

5. Y.C. Chen and Y.N. Shyu: Proc. 8th Nat. Conf. of the Chinese Society of Mechanical Engineering, Taipei, Taiwan, 1991, pp. 1115-222.

6. Y.C. Chen and G.S. Lu: J. Heat. Treat., 1992, vol. 9 (2), pp. 113-23. 